\title{
POTENTIOSTATIC CURVES OF Fe, Ni AND Co IN THE PASSIVITY AND TRANSPASSIVITY REGIONS IN FUSED $\mathrm{LiNO}_{3}-\mathrm{NaNO}_{3}-\mathrm{KNO}_{3}$ EUTECTIC*
}

\author{
J. J. Podestá, R. C. V. Piatti and A. J. Arvía \\ Instituto de Investigaciones Fisicoquímicas Teóricas y Aplicadas, División Electroquimíca, Unıver- \\ sidad Nacional de La Plata, La Plata, Argentina

\begin{abstract}
The potentiostatic current of $\mathrm{Fe}, \mathrm{Co}$ and $\mathrm{Ni}$ in molten $\mathrm{LiNO}_{3}-\mathrm{NaNO}_{3}-\mathrm{KNO}_{3}$ eutectic is studied in both the passive and transpassive regions. The processes are interpreted as the initial processes imply a change of the actual electrode area due to a localized metal corrosion. The latter depends both on the metal surface and the magnitude of the potential perturbation.
\end{abstract} \\ formation of an oxide film and as metal dissolution through the film. The various concurrent rate
}

\section{INTRODUCTION}

THE STUDY of the anodic dissolution of metals in concentrated ionic solutions at high current densities is relevant in electromachining. This process has reached an appreciable development entailed with the better knowledge of the electrochemical corrosion processes and the formation of anodic films on the metals. Most metals in real conditions, either in neutral or alkaline aqueous media, undergo electrochemical dissolution through metal/metal oxide/electrolyte interphases. ${ }^{1-6}$ The $\mathrm{pH}$ related to the thermodynamic stability of these interphases depends upon the metallic ion solvolysis equilibrium constants. The $\mathrm{Fe} / \mathrm{NaCl}, \mathrm{Fe} / \mathrm{NaClO}_{4}, \mathrm{Fe} / \mathrm{NH}_{4} \mathrm{NO}_{3}$ and $\mathrm{Fe} / \mathrm{NaNO}_{3}$ systems, either in acid, alkaline or neutral media are probably the ones more extensively investigated. ${ }^{4-6}$ The phenomenology of the corresponding processes is closely related with the dissolution of passivated metals since the anodic dissolution takes place through an oxide film which is apparently formed through a reaction mechanism involving a bi-dimensional nucleation and oxide growth on the electrode. Analogous phenomena, yielding uniform metal dissolution at high anodic potentials, were observed with iron, cobalt and nickel metals in fused nitrate melts. ${ }^{7-9}$

The present report contributes experimental results concerning the mechanism of electrodissolution of $\mathrm{Fe}, \mathrm{Ni}$ and $\mathrm{Co}$ in molten alkaline nitrates in an attempt to establish a possible potential region where uniform and controlled dissolution takes place.

\section{EXPERIMENTAL METHOD}

The Pyrex glass electrolyis cell consisted of separated compartments for the working electrode, reference electrode and counter electrode. Its description is given in previous papers. ${ }^{\rightarrow \rightarrow} \mathrm{Fe}$ plates obtained from cold rolled Ommet iron wires of $2 \mathrm{~mm}$ dia. $(99.9 \%$ were employed. Each electrode was first treated with $50 \% \mathrm{HNO}_{3}$ to eliminate surface oxides and segregated materials, then it was annealed at $950^{\circ} \mathrm{C}$ under argon during $27 \mathrm{~h}$ to obtain definite grain boundaries. Finally it was mechanically polished with No. 600 emery paper and electropolished in a perchloric acid-butyl-cellulose solution $(1: 9)$ at $0^{\circ} \mathrm{C}$ and $28 \mathrm{~V}$ with stirring. Spectroscopic Ni wire (0.5 mm dia., J. Matthey) with

*Manuscript received 30 October 1975; in revised form 7 January 1976. 
the following maximum impurities in ppm: $\mathrm{Fe}, 5 ; \mathrm{Mg}, 1 ; \mathrm{Al}<1 ; \mathrm{Ca}<1 ; \mathrm{Cu}<1$ was used after electropolishing it in the conditions already indicated. Co wires (1.0 mm dia., Koch-Light, 99.8\%) were electropolished likewise.

The counter electrode was a Pt plate of ca. $10 \mathrm{~cm}^{2}$. A bright Pt wire immersed in the molten electrolyte was used as a reference electrode to give an arbitrary but very reproducible reference potential. ${ }^{7-9}$ The fused eutectic $\mathrm{KNO}_{3}-\mathrm{NaNO}_{3}-\mathrm{LiNO}_{3}(44.5-37.5-18 \mathrm{~mol} \%$ was used as electrolyte. It was previously dehydrated under vacuum during $72 \mathrm{~h}$ at $180^{\circ} \mathrm{C}$. Experiments were made at $165^{\circ} \mathrm{C}$ using potentiostatic step techniques. Based on the stationary polarization curves, ${ }^{7-8}$ the potentiostatic potential steps were comprised between $0.35-1.5 \mathrm{~V}$. Each run was made with electropolished electrodes immediately after the immersion rest potentials had been attained, covering the passivity and transpassivity regions of the metals in the nitrate melt.

Passivated Fe electrodes were also employed. They were prepared by immersion of the metal in the melt during 5 days at $165^{\circ} \mathrm{C}$. The passivating film, which was identified by $\mathrm{X}$-ray diffractometry corresponded to $\mathrm{Fe}_{3} \mathrm{O}_{4}$. Under the same circumstances $\mathrm{Ni}$ became covered with a $\mathrm{NiO}$ film and $\mathrm{Co}$ with a $\mathrm{Co}_{3} \mathrm{O}_{4}$ film.

\section{EXPERIMENTAL RESULTS}

\section{Iron electrodes}

Current/time profiles obtained with electropolished iron electrodes under different potentiostatic steps (Fig. 1) initially involve the charging of the electrical double layer. When each profile is corrected for double layer effects, on the assumption that the corresponding electrode capacitance is $c a .50 \mu \mathrm{F} / \mathrm{cm}^{2}$, the profiles set out from the origin. The current/time response depends upon both the magnitude of the potential step and the initial potential.

The corrected curves approach at $t \rightarrow 0$ a linear relation for any potential step function but for potential steps higher than $0.40 \mathrm{~V}$ a maximum current is observed. After 3-4 ms the current approaches a low limiting value. The potential above which the maximum current is found coincides with the depassivation potential observed
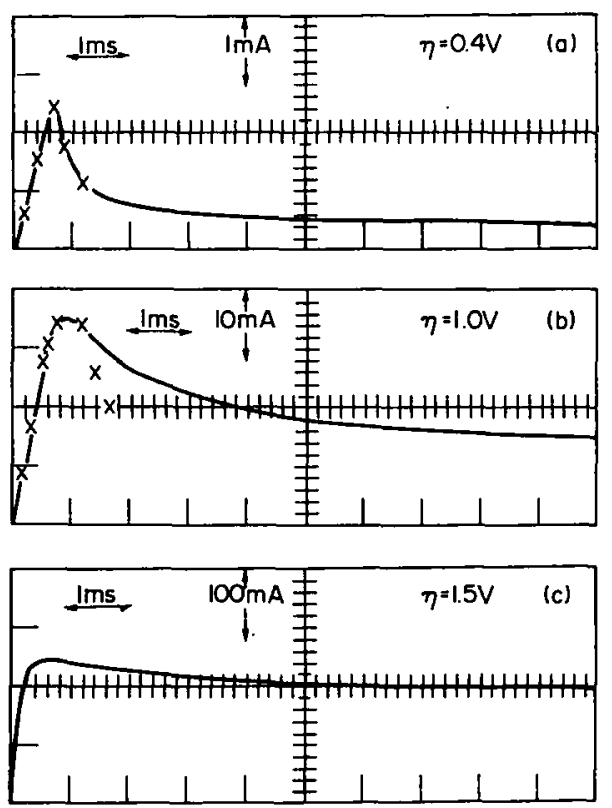

FIG. 1. Current/time profiles for electropolished Fe and different potential steps. Data calculated with equation (9) is indicated $(x)$. 
previously in the conventional current/potential curve, ${ }^{7-9}$ beyond which the metal dissolves and precipitates as $\mathrm{Fe}_{2} \mathrm{O}_{3}$ in the melt. The surface oxide formed under these circumstances was very porous. The section of the $I / t$ curve preceding the current maximum is mainly associated with the formation of the oxide film. On the other hand, when the potential step is smaller than $0.40 \mathrm{~V}$, and the starting potential is positive $(+0.1 \mathrm{~V})$, the current maximum is reached after longer times, but the residual current is much smaller. Even after $9 \mathrm{~ms}$ no stationary current is attained. A passive film which corresponds to $\mathrm{Fe}_{2} \mathrm{O}_{4}$ is observed when the overpotential step is $0.4 \mathrm{~V}$ or larger. Under these conditions the charge related to film formation can be estimated for the current/time profile (Table 1).

Table 1. Charges Related to film formation as estimated from figs. 1-4

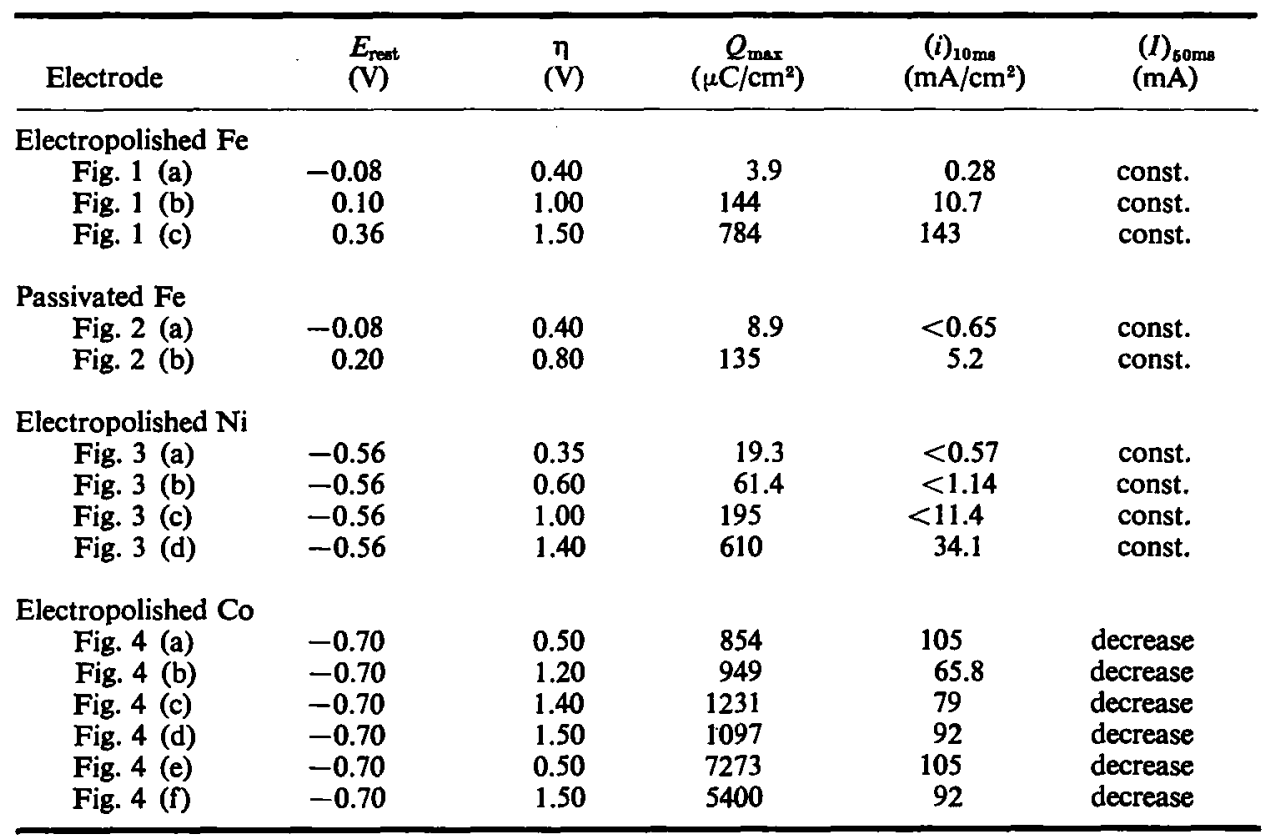

The current/time characteristics of iron samples previously oxidized (Fig. 2) are, in principle, the same as those already described for the electropolished electrodes although the charge corresponding to film formation is even smaller than that corresponding to the electropolished electrodes.

\section{Nickel electrodes}

The potentiostatic current/time curves obtained with electropolished nickel (Fig. 3) starting from a rest potential of $-0.59 \mathrm{~V}$, exhibit no residual current for small potential steps, as it corresponds to a completely passivated electrode. It should be noticed that working potentials in this case are always more positive than the passivity potential, as it is deduced from a direct comparison of these results with 

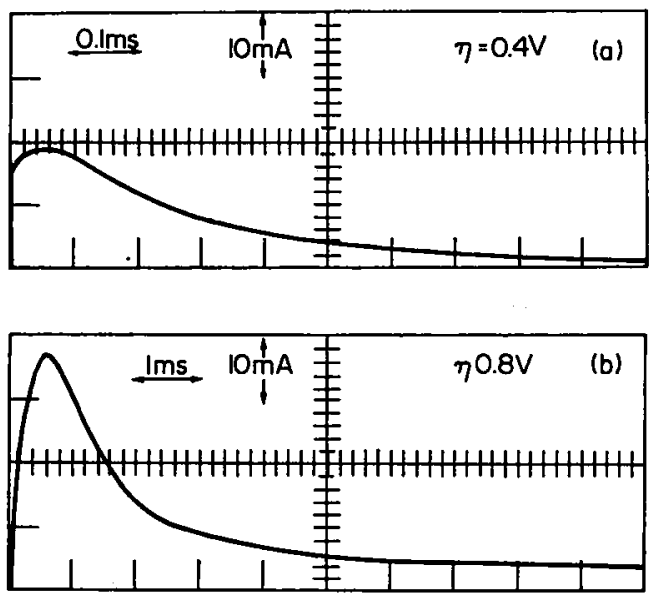

FIG. 2. Current/time profiles for passivated Fe.
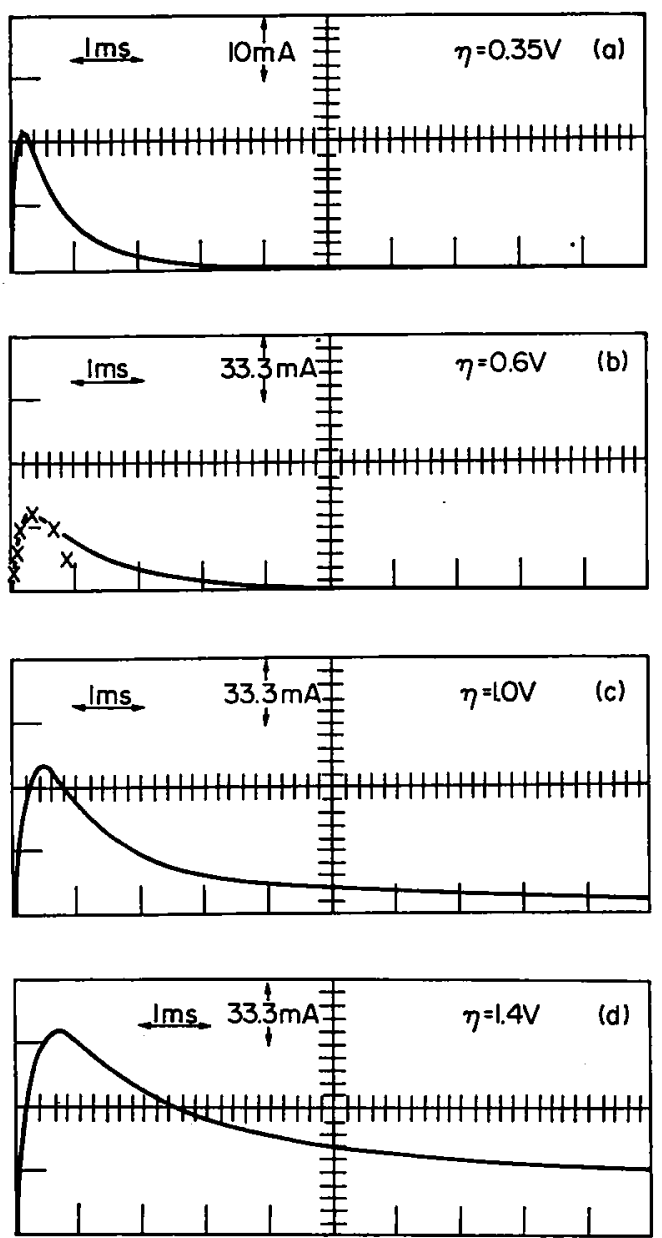

Fig. 3. Current/time profiles for electropolished Ni. Data calculated with equation (9) is indicated $(x)$. 
those derived fron potentiostatic stationary current/potential curves. ${ }^{7-8}$ The magnitude of the residual current rapidly increases with the applied potential step.

\section{Cobalt electrodes}

The $I / t$ response obtained with a potential step exhibits a current maximum which is more clearly defined with potential steps higher than $1 \mathrm{~V}$ (Fig. 4). The steady residual current is obtained after $100 \mathrm{~ms}$.
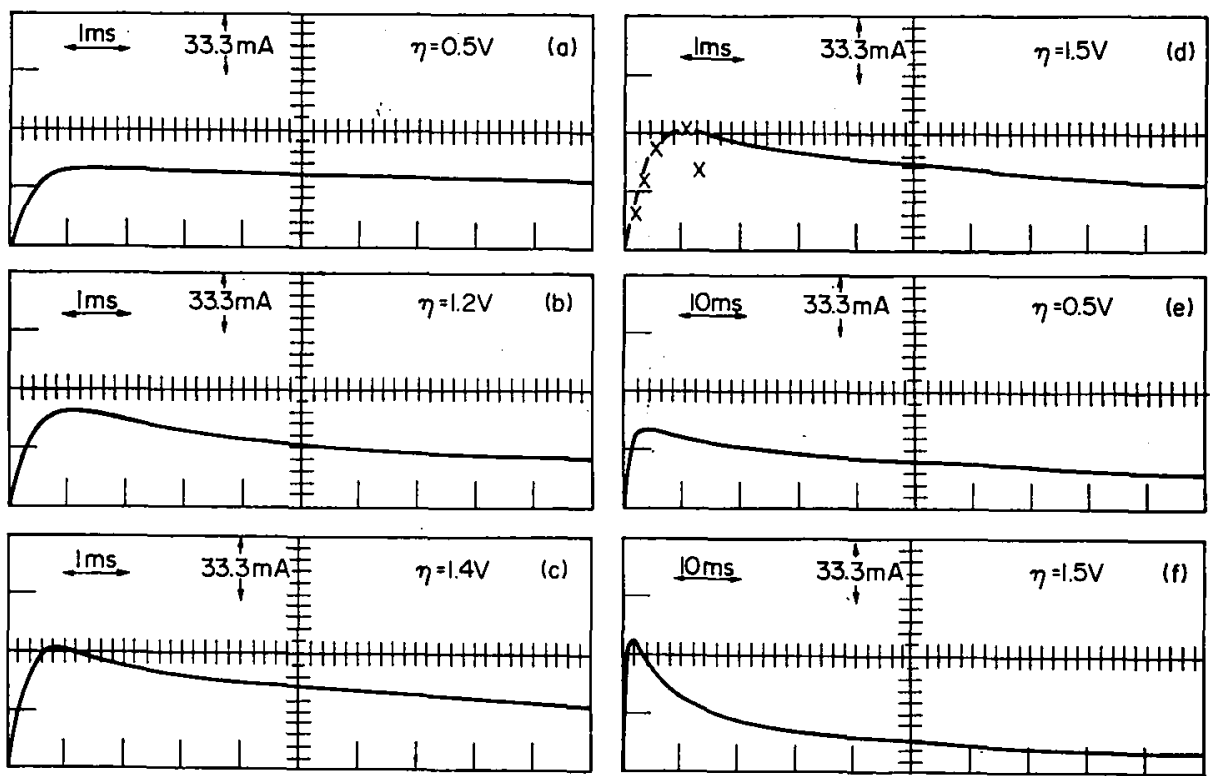

FIG. 4. Current/time profiles for electropolished Co. Data calculated with equation (9) is indicated $(x)$.

\section{INTERPRETATION AND DISCUSSION}

For the three metals the potentiostatic $I / t$ curves obtained with large potential steps, after correcting for the double layer charging process, exhibit successively a linear relationship at $t \rightarrow 0$; a maximum current, $I_{p}$, at $t=t_{p}$; and an exponential. current decrease attaining a limiting value, $I_{s}$, at $t_{\min }$. The latter is small at overpotentials between 0.35 and $0.60 \mathrm{~V}$, but increases rapidly at higher overpotentials. Both the total charge involved in the $I / t$ transient and $I_{s}$ increase with the magnitude of the potential step, while $t_{p}$ decreases with the latter. In principle, the time required to reach $I_{s}$ is much greater than that required for charging the electrical double layer. The total charge, $Q$, is:

$$
Q=\int_{o}^{t_{\min }} I . \mathrm{d} t
$$

This charge corresponds at least to three different processes, such as the charging 
of the electrical double layer, whose contribution to the total charge quantity is negligible; the charge related to film formation, and the charge due to the metal dissolution. There is no definite limit between the last two processes but most of the charge implied in the oxide formation can be estimated by integration of the corrected $I / t$ curve from $t=0$ up to the time required to reach the residual current. These $Q_{\max }$ values are indicated in Table 1 , together with the rest potential, $E_{\text {rest }}$, the overpotential step, $\eta$, and the current read after $10 \mathrm{~ms}$ of switching on.

The potentiostatic transients and the polarization curves of the three metals investigated have a close relationship. From their comparison it can be concluded that the current maximum exhibited by the $I / t$ transient corresponds in the three cases to the onset of a passive state. The formation of a passive oxide film is probably assisted by the electro-oxidation of anions present in the nitrate melt. The oxide film initially formed should attain an increasing stability until the oxide film characterizing the transpassive region forms on the surface. At this stage, under steady conditions $(t \rightarrow \infty)$ any further metal dissolution takes place through the stable oxide film..$^{7-\theta}$

The simplest explanation of the $I / t$ profile is by an ohmic type effect, according to Müller's model. If the potentiostatic $I / t$ profile is determined by an ohmic type effect, the following equation should be obeyed:10

$$
t=\tau^{\prime}+C_{2}\left[-\frac{1}{I_{p}-I}+\frac{1}{I_{p}} \ln \frac{I_{p}-I}{I}\right]=C_{1}+C_{2} f(I)
$$

$I_{p}$ is the current at the current plateau and $\tau^{\prime}$ and $C_{2}$ are constants. The former, which corresponds to the duration of the current plateau, is given by:

$$
\tau^{\prime}=\frac{\delta A g}{E_{e} I_{p} X}
$$

where $X$ is the cation transport number; $\delta$ is the oxide film thickness of geometric area $A$ and density g; $E_{e}$ is the oxide electrochemical equivalent. Equation (3) plotted as $t$ vs $f(I)$, yields by extrapolation a $\tau^{\prime}$ value which allows the evaluation of $\delta$. For this, $X$ is taken as 1 and $E_{e}=M / n .96500 . \leftrightarrow M$, the molecular weight, and $n$ correspond to the compounds $\mathrm{Fe}_{2} \mathrm{O}_{4}, \mathrm{NiO}$ and $\mathrm{Co}_{3} \mathrm{O}_{4}$ for iron, nickel and cobalt respectively. Equation (3) only reproduces the behaviour of the iron electrode transients in which $I_{s} \ll I_{p}$ (Fig. 5).

On the other hand, the possibility that the film growth becomes controlled by the dissolution rate of the metal with a porosity change, implies a relationship such as: ${ }^{1}$

$$
\ln \frac{I-I_{s}}{I_{p}}=-\frac{t}{\tau^{\prime \prime}}
$$

Equation (4) is only partly fitted at $t>t_{p}$ and from the linear region an estimation of $\tau^{\prime \prime}$ can be made. $\tau^{\prime \prime}$ is given by: 


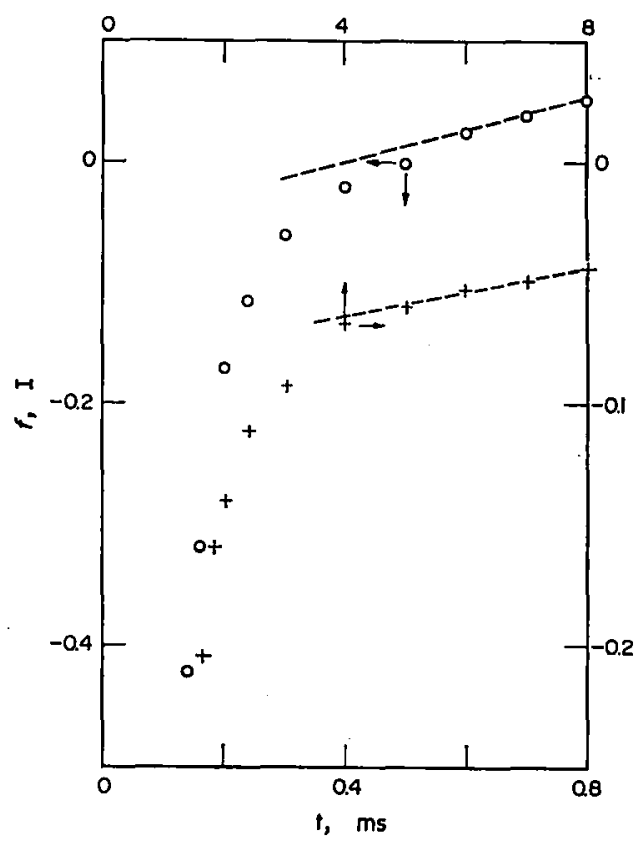

Fig. 5. Test of equation (2). (O) Passivated Fe; (+) Electropolished Fe.

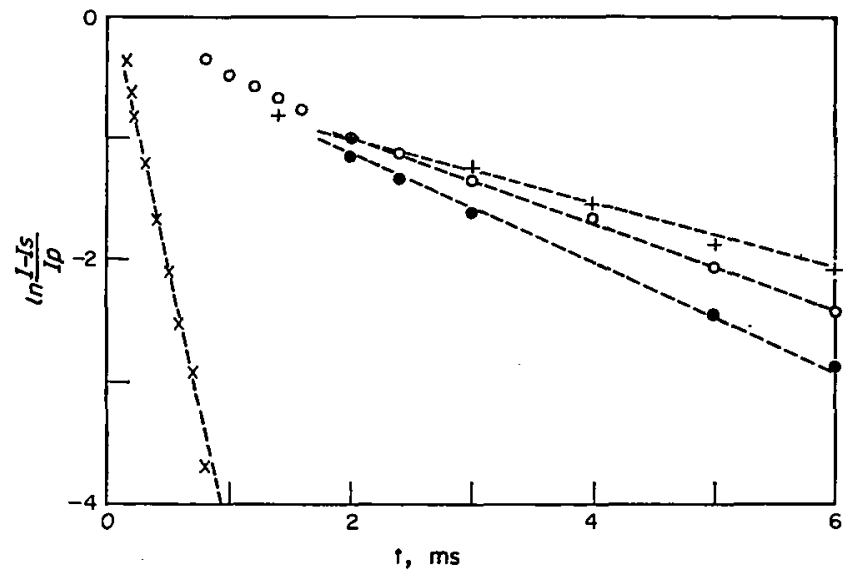

Fig. 6. Plot of equation (4). ( $\times$ ) Passivated Fe; ( $)$ Electropolished Fe; (o) Electropolished $\mathrm{Ni} ;(+)$ Electropolished $\mathrm{Co}$.

$$
\tau^{\prime \prime}=\frac{A n F \rho \delta}{\left(I_{p}-I_{s}\right) M W}
$$

Both values (Fig. 6, Table 2) are satisfactorily coincident for the three metals. This interpretation, however, is restricted only to either certain potential regions or time intervals of the transients. A more general approach is certainly required.

This can be based on the existence of three processes such as the formation of the 
TABle 2. Calculated AND EXPERIMENTALly DETERMINed VAlues of $\boldsymbol{\tau}^{\prime \prime}$

\begin{tabular}{|c|c|c|c|c|c|c|c|c|}
\hline Electrode & pxide & $\underset{\left(\mathrm{cm}^{2}\right)}{A}$ & $\begin{array}{l}\delta \\
(\AA)\end{array}$ & $\stackrel{8}{\left.\stackrel{8}{g} / \mathrm{cm}^{3}\right)}$ & $\stackrel{I_{p}}{(\mathrm{~mA})}$ & $\underset{(\mathrm{mA})}{I_{1}}$ & $\begin{array}{l}\tau^{\prime \prime}(\mathrm{malc} \text {.) } \\
(\mathrm{ms})\end{array}$ & $\begin{array}{l}\tau^{\prime \prime}(\text { exp.) } \\
(\mathrm{ms})\end{array}$ \\
\hline $\begin{array}{r}\text { Passivated } \mathrm{Fe} \\
\text { Fig. } 2 \text { (a) }\end{array}$ & $\mathrm{Fe}_{3} \mathrm{O}_{4}$ & 0.77 & 0.14 & 5.18 & 18.5 & 1.50 & 0.37 & 0.38 \\
\hline $\begin{array}{l}\text { Electropolished } \mathrm{Fe} \\
\text { Fig. } 1 \text { (b) }\end{array}$ & $\mathrm{Fe}_{3} \mathrm{O}_{4}$ & 1.40 & 0.60 & 5.18 & 35.0 & 15.0 & 2.42 & 2.38 \\
\hline $\begin{array}{c}\text { Electropolished Ni } \\
\text { Fig. } 3 \text { (d) }\end{array}$ & $\mathrm{NiO}$ & 0.88 & 1.32 & 7.45 & 106.2 & 33.3 & 3.05 & 3.03 \\
\hline $\begin{array}{l}\text { Electropolished Co } \\
\text { Fig. } 4 \text { (c) }\end{array}$ & $\mathrm{Co}_{8} \mathrm{O}_{4}$ & 0.38 & 5.43 & 6.07 & 66.6 & 34.0 & 4.09 & 4.00 \\
\hline
\end{tabular}

passive film, the electrodissolution of the uncovered metal and the electrodissolution of the metal by diffusion through the passive film. Each of these processes should be characterized by their own time constant. As a first approximation all these processes involve a constant electrode area.11,12

If the formation of the passive film principally consists of a bi-dimensional nucleation and growth process, with overlapping between the nuclei, without edge effects, and a diffusional contribution, the rate of current buildup at constant potential, is: ${ }^{11,12}$

$$
I_{\mathrm{flim}}=q_{m} \pi V^{2} N t^{2} \exp \left[-\frac{\pi}{3} V^{2} N t^{3}\right]=K_{1} t^{2} \exp -\left[\frac{t^{3}}{\tau^{3}}\right],
$$

where, $q_{m}$ is the charge associated with a complete surface layer, $V$ is the rate constant of the film growth, $N$ is the nucleation rate constant; $\tau^{3}=3 / \pi V^{2} N$, and $K_{1}=q_{m} V^{2} \pi N$. Equation (6) leads to a $I \approx t^{2}$ relation when $t \rightarrow 0$ and to $I_{\text {fim }} \rightarrow 0$ when $t \rightarrow \infty$. It predicts a maximum in the $I / t$ response.

The film-free electrode dissolution current, $I_{\mathrm{DISS}}$, may occur at certain centers or nucleus whose number may be a function of the potential. That can be expressed as follows:

$$
I_{\mathrm{DISS}}=I_{o} \exp \left[-\frac{\pi}{3} V^{2} N t^{3}\right] \text {, }
$$

where $I_{o}$ is the exchange current for the dissolution reaction occurring on the film-free electrode. Finally the dissolution rate through the film under diffusion, $I_{\text {diss, }}$, results:

$$
I_{\mathrm{diss}}=I_{a}^{\prime}\left[1-\exp \left(-\frac{\pi}{3} V^{2} N t^{3}\right)\right]
$$

$I_{o}{ }^{\prime}$ is the exchange current for the dissolution occurring on the surface covered with the passive film. If the metal is initially passivated, the preceding mechanism can be 
simplified when $I_{\text {diss }} \ll I_{\text {Diss. }}$. Under these circumstances the potentiostatic transient can be obtained by adding the main contributions:

$$
I=K_{1} t^{2} \exp \left[-\left(\frac{t}{\tau}\right)^{3}\right]+I_{o}{ }^{\prime}\left\{1-\exp \left[-\left(\frac{t}{\tau}\right)^{3}\right]\right\} .
$$

Equation (9) qualitatively reproduces the experimental results for the three metals (Figs. $1 \mathrm{a}-\mathrm{b}, 3 \mathrm{~b}$ and $4 \mathrm{~d}$ ). This model, therefore, implies that the transpassive dissolution involves oxide film participation.

This explanation can still be appreciably improved and becomes more realistic if one admits that the actual electrode area changes accordingly with the type of process predominating during the overall electrooxidation. Thus, at $t \rightarrow 0$, it is reasonable to imagine that the bi-dimensional nucleation implies an electrode area close to the geometrical area but when the metal dissolution contributes to a large extent, particularly at $t>t_{p}$, the electrode area increases appreciably with time, since the metal dissolution corresponds to a localized corrosion. Finally, when the metal dissolution takes place through an oxide film, again the electrode roughnessfactor becomes constant. Therefore, it is possible to estimate the adjusting parameter to fit the experimental and theoretical data and assign it to the electrode area change by localized corrosion. The adjusting parameter expressed as a difference between the theoretical and experimental instantaneous currents changes during the overall process (Fig. 7). The amount of charge involved in the graph depends on the metal probe and on the size of the potential pulse. The amount of charge associated with the localized corrosion increases in the order $\mathrm{Fe}<\mathrm{Ni}<\mathrm{Co}$.

The physical mechanism of the transpassivity process for these metals requires the existence of a film formation process on the electrode at a potential above the passivity potential. This is a common feature exhibited both by the passivated and initially film free electrodes. However, the estimated charge needed for the film formation is always even smaller than that required for a complete monolayer, although its magnitude increases with the size of the potentiostatic step. This matter, however, indicates the rupture of the film at potentials lying above the passivity potential. In these circumstances the surface localized region where the film breaks is re-oxidized. The charge associated with this process is necessarily smaller than that required for a complete monolayer, approaching this value only when the film completely disappears.

The interpretation advanced for these electrode processes implies some interesting consequences. Thus, the number of cracks produced should depend on the applied potential step. Once the rupture potential is reached, the mechanical properties of the film are overcome by the electrostriction effect. Therefore, the film exhibits no cohesion and the metal dissolution yields to oxide suspension in the melt. The metal dissolution above the rupture potential implies a localized corrosion. This type of corrosion is actually observed for the three metals.

In conclusion, these results indicate that the initial transpassivity process of $\mathrm{Fe}, \mathrm{Ni}$ and $\mathrm{Co}$ in the molten alkaline nitrates implies oxide film rupture. This process may fit the physical model proposed by Sato. ${ }^{13}$ At the same time the transpassive region is related to a localized corrosion. The stable oxide is always formed but it has 

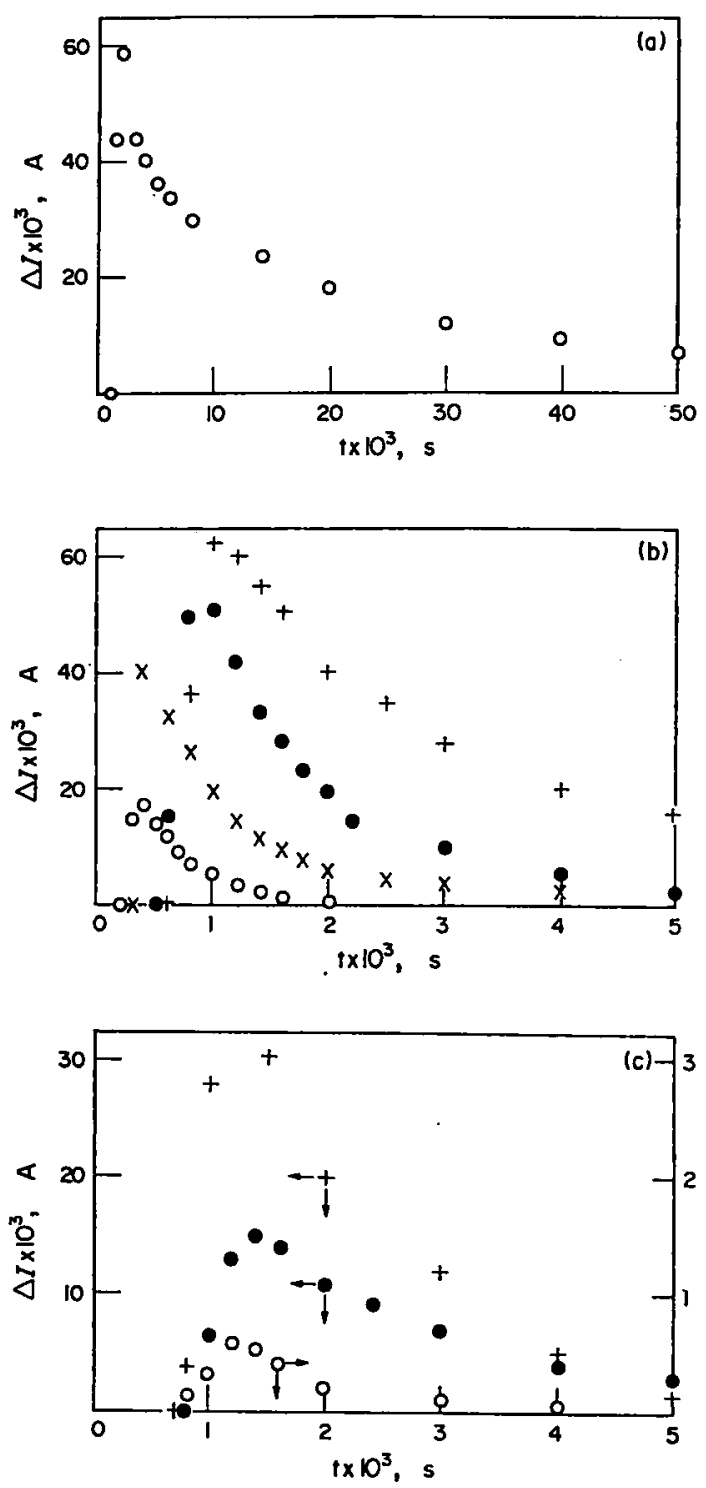

FIG. 7. Time dependence of the surface change parameter. (a) Electropolished $\mathrm{Co}$; (b) Electropolished $\mathrm{Ni}(+) 1.4 \mathrm{~V} ;(\bullet) 1.0 \mathrm{~V} ;(\times) 0.6 \mathrm{~V} ;(0) 0.35 \mathrm{~V}$; (c) Electropolished $\mathrm{Fe}(t) 1.5 \mathrm{~V} ;(\bullet) 1.0 \mathrm{~V}(0) 0.4 \mathrm{~V}$.

a poor adhesion to the metal surface. An explanation of these phenomena based upon local changes of the concentration of certain ionic species or a change of basicity of the medium is difficult to sustain although it is not rejected. These changes may probably play a more significant role in the transpassivity process under quasisteady conditions. 
Acknowledgement-This work is part of the ECOMAR I project sponsored by the Servicio Naval de Investigación y Desarrollo of the Argentine Navy and the Consejo Nacional de Investigaciones Cientificas y Técnicas of Argentina. J. J. Podestá acted as a Faculty Member of the Chemical Engineering Department of the Universidad Nacional de La Plata.

1. D-T. CHIN, J. electrochem. Soc. 118, 174 (1971).

\section{REFERENCES}

2. D-T. CHIN, J. electrochem. Soc. 119, 1043 (1972).

3. D-T. CHIN, J. electrochem. Soc. 119, 1181 (1972).

4. J. P. HoARE and K. W. MAO, J. electrochem. Soc. 120, 1452 (1973).

5. K. W. MAO, M. A. LA BODA and J. P. HoARE, J. electrochem. Soc. 119, 419 (1972).

6. D-T. CHIN and A. J. WALlaCE, J. electrochem. Soc. 120, 1487 (1973).

7. A. J. Arví, R. C. P. Piatti and J. J. Podestá, Electrochim. Acta 17, 901 (1972).

8. A. J. Arví, J. J. PodestA and R. C. V. Piatti, Electrochim. Acta 17, 33 (1972).

9. J. J. Podestá, R. C. V. Piatti and A. J. Arvía, J. appl. Electrochem. 3, 241 (1973).

10. W. J. Müller, Trans. Faraday Soc. 27, 737 (1931).

11. R. D. ARmstrong, D. F. Porter and R. H. THIRsk, J. phys. Chem. 72, 2300 (1968).

12. R. D. ARmstrong, G. M. Bulman and H. R. Thirsk, J. electroanal. Chem. 22, 55 (1969).

13. N. SATo, Electrochim. Acta 16, 1683 (1971). 